\title{
Understanding (non)leadership phenomena in collaborative interorganizational networks and advancing shared leadership theory: an interpretive grounded theory study
}

\author{
Sigrid Endres ${ }^{1}$ (D) Jürgen Weibler ${ }^{1}$
}

Received: 30 January 2018/ Accepted: 7 January 2019/Published online: 16 January 2019

(C) The Author(s) 2019

\begin{abstract}
Despite the increasing significance of collaborative interorganizational networks, understanding of leadership phenomena in these contexts is still scarce. How, and in what form will leadership emerge in such (a priori) non-hierarchical contexts with peerlike work settings, if at all? Through an interpretive grounded theory study conducted in collaborative interorganizational networks, we found that the networks either remained at the stage of leaderless cooperation (leadership void) or developed shared leadership. We then sought to understand the underlying mechanism of collaboration that might explain the different (non)leadership phenomena. Our study's main result is the empirically grounded identification of two distinct forms of network participation with specific network identities as its core, which are related to the distinct leadership-related phenomena in our networks. (1) Task-based network identity, which includes an individualistic network identity, a single achievement motivation, and a largely instrumentalist orientation towards network participation, is related to a leadership void (non-leadership emergence, i.e. a form of leaderless cooperation). (2) Joint-motivational network identity, which includes a collectivistic network identity, joint network motivation, and a largely value-laden attitude towards network participation, is related to shared leadership. Our findings shed new light on collaboration and leadership phenomena in interorganizational networks, concurrently providing progress on conceptualizing
\end{abstract}

Electronic supplementary material The online version of this article (https://doi.org/10.1007/s40685019-0086-6) contains supplementary material, which is available to authorized users.

Sigrid Endres

Sigrid.Endres@Fernuni-Hagen.de

Jürgen Weibler

Juergen.Weibler@Fernuni-Hagen.de

1 Faculty of Business Administration and Economics, Chair of Business Administration, Leadership and Organization, University of Hagen (FernUniversität in Hagen), 58084 Hagen, Germany 
shared leadership, in particular by introducing joint-motivational network identity as a new concept related to shared leadership development. We discuss implications for the management of collaborative interorganizational networks and advance theory on plural forms of leadership such as collective or shared leadership.

Keywords Leadership in interorganizational networks · Collective/shared leadership · Plural leadership · Self-managing/self-governing organization · Non-hierarchical context · Network identity · Interpretive grounded theory approach

\section{Introduction}

Collaborative non-hierarchical and network forms of organizing are without doubt in vogue. Many scholars argue that the traditional hierarchical organization form should be-and actually is-increasingly enriched by more collaborative, crossorganizational and network forms of organizing, to cope with the challenges posed by wide-reaching changes taking place in society, the economy, and technology (e.g. Raab and Kenis 2009; Miles et al. 2010). And indeed, against a multifaceted discussion of future challenges for contemporary organization and management, collaborative interorganizational networks (Powell 1990; Provan et al. 2007) have gained significantly in importance (e.g. Clegg et al. 2016; Gulati et al. 2012; Miles et al. 2010; Fjeldstad et al. 2012; Barringer and Harrison 2000). Given this prevalence and significance of interorganizational networks, it is remarkable that scholars have paid little attention to network internal leadership processes, which are considered as a significant part of an interorganizational network's overall functioning mechanisms (Davis and Eisenhardt 2011; Denis et al. 2001; Huxham and Vangen 2000). Curiously enough, leadership in interorganizational networks is often mentioned but rarely studied empirically (Connelly 2007; Müller-Seitz 2012). Moreover, existing research on leadership in interorganizational networks has been predominantly on organizational and macro levels and has focused on the guidance of lead firms. Thus, researchers have in particular neglected interactional microlevel processes and interpersonal leadership (Müller-Seitz 2012). As our literature review will show (see Sect. 2.3), it is still unclear, how leadership actually happens among individuals in collaborative interorganizational networks. There is a need to learn more about what leadership types, behaviors, or practices might be required in this context, in which individuals as representatives of legally autonomous member firms participate voluntarily and without formal employment contracts (see Sect. 2.1).

The main purpose of our study, therefore, was to provide insight into network leadership phenomena in collaborative interorganizational networks in which formally independent members participate to achieve overarching objectives (Powell 1990; Provan et al. 2007; Miles et al. 2010; cf. Sect. 2.1). We pursued our goal by studying interactions and emerging pattern of network participation and potentially emerging leadership phenomena via an interpretative grounded theory study in different but comparable collaborative interorganizational networks. As 
suggested for interpretive grounded theory research, we seek to relate our study's (final) result back to corresponding literature in order to develop a sound theoretical contribution (Suddaby 2006; Charmaz 2014). Since shared leadership emerged as empirically grounded main theme, in the end we were able to advance theory on plural forms of leadership such as collective or shared leadership (cf. Sect. 5.2).

Given the nascent status of theorizing on leadership in interorganizational collaborative networks and based on the reasoning provided above, our research centers around three relatively open questions with respect to the nature of leadership in collaborative interorganizational networks and the generative sources of leadership emergence. First, we ask, "How and in what form, if at all, will leadership emerge in the networks?" We took both single and plural forms of leadership (e.g. shared or collective leadership) into consideration without, however, expecting any specific form. We refer to the networks with the pseudonyms "BlueNet" and "RedNet". We observed how, both in BlueNet and RedNet, no individual emerged as a single network leader. Beyond this overarching rejection of single leadership, however, we revealed two distinct leadership-related phenomena. The RedNet actors developed collectively shared leadership processes, whereas the BlueNet actors remained at the stage of leaderless network cooperation (i.e. no single participant emerged as a leader, nor did the collective become engaged in leadership processes). We attempted to understand how and why these (non)leadership phenomena occurred in such different ways in networks that in other respects were rather similar. Therefore, our second question was "What might contribute to explain these different (non-)leadership phenomena?" Finally, we wanted to discover how far these dynamics could be forged by network coordinators or persons in similar more formal roles, so that our third question was "What are significant differentiation features in the network coordinators' main activities that might contribute to facilitating emerging different (non)leadership phenomena?"

As our findings will show, we identified two distinct forms of network participation with specific network identities as its core, which are related to the distinct (non)leadership phenomena in our networks. On this basis, our findings suggest first that a task-based network identity, which includes an individualistic network identity, a single achievement motivation, and a largely instrumentalist orientation towards network participation, is related to a leadership void (i.e., a form of leaderless cooperation). Second, that a joint-motivational network identity, which includes a collectivistic network identity, joint network motivation, and a largely value-laden attitude towards network participation, is related to shared leadership. We combined the components - together with further crucial conditions with regard to the network coordinators' function-to a grounded theoretical model for understanding (non)leadership phenomenon better in the light of distinct network identity pattern.

Through attending to the network participants' perceptions, language, and experiences, we were able to shed light on their views and practices of network cooperation and leadership and to provide practical and theoretical insights into network leadership and on the dynamics of their emergence, a phenomenon that is still poorly understood. Overall, our study's contribution centers around two main fields. First, we extend the existing literature on leadership in collaborative 
interorganizational networks (e.g. Huxham and Vangen 2000; Miles et al. 2010; Ospina and Saz-Carranza 2010; Weibler and Rohn-Endres 2010; Feyerherm 1994; Denis et al. 2001; Davis and Eisenhardt 2011) by elucidating the network internal functioning mechanisms, in particular by revealing both the collective nature of their leadership and the identity-based source of network leadership emergence. Second, our study's results advance the emerging theory on plural leadership forms such as collective or shared leadership (e.g. Avolio et al. 2009; Denis et al. 2012; Sergi et al. 2012; Dust and Ziegert 2016; Fitzsimons et al. 2011; Nicolaides et al. 2014; Endres and Weibler 2017). We shed light on the underlying generative mechanism of shared leadership development by our newly developed jointmotivational network identity and offer conceptual progress on how to distinguish shared leadership processes from other collective-level phenomena (e.g. team working or system-wide organizing processes; cf. Endres and Weibler 2017; Blom and Alvesson 2015; Denis et al. 2012).

\section{Theoretical foundations and background}

Theory, on the one hand, is the research result that emerged after we developed our findings through an interpretive grounded theory approach (cf. Sect. 3) and is presented toward the end of our paper. On the other hand, in line with our methodology, theory is a source for concept development and/or refinement, and thus, theoretical assumptions should be made explicit (Suddaby 2006; Charmaz 2014; Ridder 2017). In the following, we provide information on collaborative interorganizational networks, and the study of leadership in this context, as well as on the basic assumptions of our leadership approach. Further explication of theoretical concepts relevant to our findings and the emerging grounded theoretical model are delivered in the context of the discussion of our study's results.

\subsection{Collaborative interorganizational networks}

We study leadership at the interactional level in collaborative interorganizational networks which are understood as intentionally created social entities of three or more organizations in which legally autonomous members participate to achieve overarching objectives (Powell 1990; Provan et al. 2007; Miles et al. 2010). This definition implies that members have a perception of the network's overall purpose that is, however, usually unrelated to specific goals. The term 'legally autonomous' means that member organizations' relationships are characterized by the absence of any a priori existing formal guidance of a lead firm (cf. Miles et al. 2010; Provan et al. 2007; Huxham and Vangen 2000; Weibler and Rohn-Endres 2010). However, this definition does not imply any assessments of the actual interaction quality of the individual network actors, which we refer to here as individual representatives of the organizations constituting the network.

Our understanding of the term network is related to the interorganizational or network governance perspective, which basically understands interorganizational networks as a substantive form of organizing (Provan et al. 2007; Jones et al. 1997; 
Powell 1990). In the literature, this perspective is usually contrasted with the structuralist or social network analytical perspective, which refers to networks in a more formal sense using social network analysis. Here, networks are basically understood as an abstract notion and referred to as "a set of actors connected by a set of ties" (Borgatti and Foster 2003: 992). In contrast, networks from a network governance perspective are understood as a distinct form of coordination and exchange between usually autonomous firms or organizations. The term network governance refers to a form of inter-firm or inter-organizational coordination that is characterized "by informal social systems rather than by bureaucratic structures within firms and formal contractual relationships between them" (Jones et al. 1997: 911). This form of coordination thus relies more on socially committing as contrasted to legally binding contracts. The members can be linked by many types of connections and exchange flows (e.g. information, social support, services, materials) (Provan et al. 2007; Jones et al. 1997; Powell 1990). Such networks are characterized by an "inherent pluralism embedded in their structures and modes of working" (Sergi et al. 2012: 406). Hence, a key challenge for network management is to channel preexisting pluralism in order to advance the collaborative network agenda. In this context, the literature points to the complex and ambiguous nature of collaboration in networks that generates paradoxes and tensions for their management (Ospina and Saz-Carranza 2010; Vangen and Huxham 2003).

The networks selected for our study had a relatively similar collaborative form, i.e. the member organizations' intention is to work together and exchange knowledge and experience on specific themes. In line with Huxham and Vangen (2000: 1159), we use the term "collaborative" to describe organizations (rather than just individuals) that are working together. Further, the networks had a similar thematic orientation (i.e., health, occupational and environmental protection, and industrial safety) and were primarily composed of member firms from the profit sector (cf. Sect. 3.2).

\subsection{Leadership}

We understand leadership basically as a dynamic socially constructed influence process (Endres and Weibler 2017; Alvesson 2017; Uhl-Bien 2006; Hannah et al. 2014). The social constructionist leadership perspective has gained significant in importance more recently, since there is an increasing recognition of the need for a less individual-centred, more dynamic, processual view of leadership in organizations (cf. Uhl-Bien and Ospina 2012; Endres and Weibler 2017 for an overview and conceptual synthesis). More recently, for example, Wellman (2017: 614) similarly points to the dynamic realities of leadership in contemporary organizations which involve significant challenges for leadership theorizing, and he currently observes an emerging "need for new leadership models that acknowledge that leadership is socially constructed between the members of a group and is shaped in fundamental ways by the group context". Approaching leadership as a socially constructed phenomenon is in line with our study's interpretive methodological foundation, and involves the following basic assumptions and key characteristics: first, the basic mechanism of leadership is social construction, i.e. "processes of intersubjectively 
creating social realities through ongoing interpretation and interaction" (Endres and Weibler 2017: 222; cf. Uhl-Bien 2006; Ospina and Saz-Carranza 2010; Astley 1985; Morgan and Smircich 1980). Second, the social constructionist leadership approach seeks to deepen understanding of the intersubjective day-to-day experience and practices of people and how they are co-constructing leadership processes, instead of identifying 'objective' laws of human behaviour. In consequence, third, leadership as such is a process constructed in interactions between individuals via ongoing interpretations. This ontological process perspective of leadership implies that leadership is not (necessarily) tied to a formal (or hierarchical) leadership position. Therefore, social constructionist approaches explicitly avoid conflating leadership with supervision or formal guidance, and pay attention to potentially emerging organization wide (informal) leadership processes, as highlighted by Endres and Weibler (2017: 227; cf. Alvesson 2017; Uhl-Bien 2006). Finally, and fourth, a necessary component of leadership then is influence, i.e. "emerging flows of influence at the interpersonal interaction level or the collective level that represent the leadership manifestation" (Endres and Weibler 2017: 226; cf. Alvesson 2017). Hence, this process-oriented leadership approach takes into consideration that from the social construction process among individuals, both single leadership and shared (or collective) leadership, as well as hybrid forms, may emerge. In the literature, the term "shared leadership" is usually used interchangeably with "collective leadership", and describes a plural form of leadership (cf. Avolio et al. 2009: 431; Denis et al. 2012; see Sect. 5 for more details).

From an identity-related perspective, which will gain significant relevance in our conducted study, DeRue and Ashford (2010) argue that leadership only occurs when others grant or ascribe leadership, and that individuals construct and internalize a leader or follower identity and that these identities become recognized by other members. In related fields, there have also been attempts to explain how and why a priori equal group members gain credit based on status ascriptions that allow them to exert influence and to emerge as a leader of the group (e.g. Hollander 1974; Paunova 2015; Stone and Cooper 2009). This approach also fits in with our approach in that it is open enough to examine emerging leadership inductively and embedded in context-specific interactions.

\subsection{Literature review on leadership in collaborative interorganizational networks}

Despite its widely acknowledged importance, individual actors' leadership and interaction-related leadership processes within networks have been rarely assessed empirically (cf. Jack 2010; Provan et al. 2007; Connelly 2007). For example, in a systematic review of interorganizational leadership, Müller-Seitz (2012) found only four empirical (qualitative) studies on the individual level of leadership (i.e., Beyer and Browning 1999; Martin et al. 2009; Ritala et al. 2009; Saz-Carranza and Ospina 2011). A further exploration of these sources shows that Beyer and Browning (1999) in their study of charismatic leadership in a consortium described the development of a joint vision through "cultural leadership" that influences how "followers collectively think and act" (1999: 485). Martin et al. (2009) pointed to 
the need for distributed leadership forms for achieving change in public service networks (see also Currie et al. 2011). Ritala et al. (2009) investigated individual skills and organizational capabilities and their interplay in successful innovation network management. Finally, given the identified research gaps, Müller-Seitz (2012) traced the "incoherence" of the literature on leadership in interorganizational networks and also pointed to the need for becoming "better engaged with classical research on interpersonal leadership" (2012: 438) and on interpersonal issues for developing a more comprehensive understanding of leadership in interorganizational networks.

Indeed, only a few additional empirical studies address this momentous topic. For example, in an early longitudinal study in two rule-making groups, Feyerherm (1994) — based on an interaction-oriented approach-revealed the informal, emergent nature of leadership in such collaborations. Similarly and based on a qualitative action research design, Huxham and Vangen (2000) emphasized the emergent nature of leadership and conceptualized leadership as "the mechanisms that "make things happen' in a collaboration" (2000: 1165). In this view, leadership occurs through "leadership media," comprising structures, processes, and participants, as well as through "leadership activities," carried out by participants to promote the "collaborative agenda" (Huxham and Vangen 2000: 1165ff.). In line with this research, but focusing on individual network managers, Vangen and Huxham (2003) revealed the contradictory demands on "partnership managers" who become involved in both facilitative and directive leadership roles while organizing the collaboration's activities. Tensions and dilemmas were also an important topic in Sydow et al.' (2011) study of cluster management. They identified a "silent cry paradox" which should be "managed" by "organizing for leading (in) clusters" based on "reflexive structuration" (Sydow et al. 2011: 339). Ospina and SazCarranza (2010) addressed another paradox-namely, the "unity and diversity paradox" in network management-and concurrently described a set of practices as a response to the paradoxical and complex requirements of network collaboration. In a similar vein, Weibler and Rohn-Endres (2010) focused on interaction and practices, and finally portrayed leadership in interorganizational networks as occurring through the interplay of structures, individuals, and the collective-and developed the notion of shared network leadership as dialogue practice. Focusing more on the outcomes of leadership, Davis and Eisenhardt (2011) conducted a comparative case study in eight technology collaborations and found that what they termed "rotating leadership" was superior in eliciting innovation compared to both "dominating leadership" and "consensus leadership" (2011: 159). Denis et al. (2001) also found a relation between specific leadership processes and outcomes. They highlighted the importance of shared leadership in promoting change and pointed to the fragility of such leadership constellations.

While all these studies are informative and relevant taken together, they still do not clarify what leadership types, behaviors, or practices might be required in interorganizational networks in which individuals participate of their own accord and without formal fiat or based on employment contracts. This implies providing rich context-sensitive descriptions of team and leadership phenomena in practice and moving beyond narrow theoretically (pre-)framed or prescriptive accounts (cf. 
Hannah et al. 2014; DeRue and Ashford 2010; Blom and Alvesson 2015). Similarly, Endres and Weibler (2017) showed that there is a significant need for research that does not start with 'leadership', or what is assumed to be leadership, but rather with interaction dynamics and practices as they occur in a specific setting.

\section{Methods}

Considering the emergent character of our research topic, we adopted a qualitative, interpretive grounded theory approach (Charmaz 2014; Suddaby 2006; Glaser and Strauss 1967) that allowed us to study on a context-sensitive basis emerging network leadership phenomena that are still poorly understood (Edmondson and McManus 2007). Given the various versions of grounded theory methodology (Glaser and Strauss 1967; Strauss and Corbin 1998; Charmaz et al. 2018), we briefly introduce the basic assumptions/core principals of the interpretive grounded theory approach.

\subsection{Foundations and principles of interpretive grounded theory}

Interpretive grounded theory (Charmaz 2014; Suddaby 2006; Glaser and Strauss 1967 ) is usually contrasted with a positivist approach of qualitative research (cf. e.g. Gephart 2004 on the distinction between positivist and non-positivist/interpretive qualitative research). From an interpretive perspective, "truth" is considered as provisional, and social life as well as leadership as processual (Charmaz 2014: 17; Charmaz et al. 2018; cf. Endres and Weibler 2017: 217f.; cf. Astley 1985; Morgan and Smircich 1980). Hence, research "seeks interpretive understanding rather than a variable analysis that produces abstract generalizations" (Charmaz et al. 2018: 417; Suddaby 2006). Through attending to our participants' perceptions, language, and experiences, our study sheds light on their views and practices of network leadership, and provides new theoretical insights on (non)leadership phenomena in collaborative interorganizational networks and on shared leadership development. We developed our findings through analytic induction by iteratively shifting between data-inspired induction and theory-inspired deduction for imaginative practice-oriented theorizing (Suddaby 2006; Charmaz 2014). In doing so, we rely on informed grounded theory, which is neither abstract (or naive) empiricism nor pure (subjectivist) relativism. Hence, grounded theory "is not an excuse to ignore the literature" (Suddaby 2006: 634; Charmaz et al. 2018: 419; Charmaz 2014). In line with this understanding, we applied "constant comparison" and "theoretical sampling", which are considered core principles of grounded theorizing (Suddaby 2006; Charmaz 2014; Glaser and Strauss 1967). Constant comparison fundamentally implies an iterative cyclical research process in which the researcher shifts between collecting and analyzing data (see below for more details). Theoretical sampling means making decisions on what data to collect next on the basis of themes and concepts that emerged with theoretical relevance for the theory that is being constructed (cf. Charmaz 2014; Suddaby 2006: 634). This involves primarily "seeking and collecting data to elaborate the properties of the researcher's 
theoretical categories but also to define variation within a category and to specify relations between categories" (Charmaz et al. 2018: 424). Applying this strategy helps researchers to stay focused, and prevents them from becoming overwhelmed by the amount of data and potentially relevant concepts (Charmaz et al. 2018). Hence, when applying these principles researchers break with "the myth of a clean separation between data collection and analysis" and replace the positivist notion of testing a hypothesis by the notion of ongoing interpretation and shifting between data and emerging theoretical categories (Suddaby 2006: 634; cf. Charmaz 2014).

\subsection{Study setting and research context}

We pursued our research in three collaborative interorganizational networks with member firms from the for-profit sector. We pseudonymized the networks as RedNet and BlueNet1/BlueNet 2 (referred to as "BlueNet" because we clustered these networks for empirical reasons). Given our research interest in interactions and emerging (informal) leadership activities, the fundamental criteria for inclusion in the sample were that all networks (1) have an ongoing activity, including regular face-to-face interactions; (2) have comparable organizing processes based on their similar collaborative non-hierarchical structure based on a lack of (a priori given) guidance structures, and (3) have a similar thematic focus (i.e. occupational/ environmental protection, industrial safety/health, see Table 1 for more information about the networks' descriptive characteristics).

\subsection{Data sources}

We included a wide range of data types gathered from different sources. Table 2 contains a detailed description of data sources-interviews, observations of network meetings, document analysis - and includes information on how we used the data in our knowledge generation process.

The interviews, which included partly open-ended questions and partly focused questions, on the one hand were open enough to capture our participants' experiences, and on the other hand permitted us to become more focused on emerging theory. The combination of "open-ended inquiry" and "focused attention" is a key characteristic of intensive interviewing (Charmaz 2014: 85ff). This strategy is recommended for grounded theory research, because it enables the researcher both to learn from participants what happens in the field and to generate "focused data" for developing theoretical enriched categories (Charmaz 2014: 87). In particular in the early research phase, and throughout the whole research process, we included open questions at the outset of each interview. Although our list of issues changed constantly to accommodate both emerging themes and our increasing understanding, we included similar questions on some issues to evaluate and better compare the themes. We started with a general request that participants recount experiences with network participation. We were particularly interested in concrete inter/actions and events, and commonly included questions about our participants' perceptions of (1) network relationships and activities (e.g. meeting procedures, decision-making processes), (2) results achieved, (3) ways of 
Table 1 Formal network descriptive characteristics

\begin{tabular}{|c|c|c|c|}
\hline Characteristic & RedNet & BlueNet1 & BlueNet2 \\
\hline $\begin{array}{l}\text { Structure, } \\
\text { institutional } \\
\text { setting, and } \\
\text { administration }\end{array}$ & $\begin{array}{l}\text { Consciously created; } \\
\text { collaborative network } \\
\text { structure }^{\text {a }} \text {; registered } \\
\text { association; network } \\
\text { administration provided } \\
\text { by a coordination office } \\
\text { (three persons who are } \\
\text { not member firm } \\
\text { representatives) }\end{array}$ & $\begin{array}{l}\text { Consciously created; } \\
\text { collaborative network } \\
\text { structure } \text {; organized } \\
\text { similar to an association; } \\
\text { network administration } \\
\text { provided by a } \\
\text { coordinating group of two } \\
\text { formally assigned firm } \\
\text { representatives (supported } \\
\text { by two members of a } \\
\text { government agency for } \\
\text { the promotion of } \\
\text { economic development) }\end{array}$ & $\begin{array}{l}\text { Consciously created; } \\
\text { collaborative network } \\
\text { structure }^{\mathrm{a}} \text {; organized } \\
\text { similar to an association, } \\
\text { network administration } \\
\text { provided by one formally } \\
\text { assigned coordinator in } \\
\text { cooperation with different } \\
\text { firm representatives }\end{array}$ \\
\hline Year formed & 1994 & 2005 & 2003 \\
\hline $\begin{array}{l}\text { Organizational } \\
\text { members }^{\mathrm{b}}\end{array}$ & $\begin{array}{l}\text { About } 60 \text { companies (for- } \\
\text { profit sector) varying in } \\
\text { size (from small- and } \\
\text { medium-sized firms to } \\
\text { major corporations), and } \\
\text { branches with an interest } \\
\text { in environmental } \\
\text { protection and sustainable } \\
\text { development, focusing on } \\
\text { ecological points of view }\end{array}$ & $\begin{array}{l}\text { About } 30 \text { companies/ } \\
\text { organizations (primarily } \\
\text { for-profit-sector), varying } \\
\text { in size (from small- and } \\
\text { medium-sized firms to } \\
\text { major corporations) and } \\
\text { branches, all having an } \\
\text { interest in environmental } \\
\text { protection management; } \\
\text { four associate members } \\
\text { (e.g., local chamber of } \\
\text { industry and commerce; } \\
\text { government agency for } \\
\text { the promotion of } \\
\text { economic development) }\end{array}$ & $\begin{array}{l}\text { About } 20 \text { companies (for- } \\
\text { profit-sector) varying in } \\
\text { size (from small-and- } \\
\text { medium-sized firms to } \\
\text { major corporations), and } \\
\text { branches, all having an } \\
\text { interest in health, } \\
\text { occupational, and } \\
\text { environmental protection, } \\
\text { and industrial safety }\end{array}$ \\
\hline $\begin{array}{l}\text { Network } \\
\text { objectives and } \\
\text { activities }\end{array}$ & $\begin{array}{l}\text { Promoting protection of the } \\
\text { environment; sensitizing } \\
\text { companies, institutions, } \\
\text { politics, and the public for } \\
\text { questions of } \\
\text { environmental, consumer } \\
\text { protection, while focusing } \\
\text { on ecological aspects; } \\
\text { exchanging views and } \\
\text { experiences amongst the } \\
\text { network participants } \\
\text { (discussion platforms, } \\
\text { advanced workshops, } \\
\text { expert reports; company } \\
\text { visits); developing joint } \\
\text { strategies for market } \\
\text { development; public } \\
\text { relations work; lobbying }\end{array}$ & $\begin{array}{l}\text { Promoting protection of the } \\
\text { environment; sensitizing } \\
\text { companies, organizations } \\
\text { for questions of } \\
\text { environmental protection; } \\
\text { exchanging views and } \\
\text { experiences amongst the } \\
\text { network participants } \\
\text { (workshops, discussion } \\
\text { platforms, expert reports; } \\
\text { company visits); } \\
\text { providing access to } \\
\text { advisory services }\end{array}$ & $\begin{array}{l}\text { Promoting occupational and } \\
\text { environmental protection; } \\
\text { sensitizing companies and } \\
\text { organizations for } \\
\text { questions of occupational, } \\
\text { and environmental } \\
\text { protection; exchanging } \\
\text { views and experiences } \\
\text { amongst the network } \\
\text { participants (knowledge } \\
\text { data base, discussion } \\
\text { platforms, advanced } \\
\text { workshops, expert } \\
\text { reports; company visits) }\end{array}$ \\
\hline
\end{tabular}

\footnotetext{
${ }^{a}$ Because we here intended to provide only a preliminary description of network structures, we refer to "collaborative network structure" in terms of the absence of any a priori formal guidance of one or more lead firms (see, e.g. Miles et al. 2010)

because there are always some "passive members", the number of formal organizational members may be slightly larger than the number of actual network actors. Network actors in terms of our study are individual representatives of the organizations constituting the network
} 
organizing, and (4) network members' motivations or goals for network participation. Similarly, coordinators were asked about network processes, their tasks, and activities. We further included a general request to comment on leadership if the subject had not been previously addressed. However, we did not explicitly ask about "identity", but we were interested in our interviewees' motivations, orientations, and beliefs about their network participation. We also conducted feedback dialogues (cf. Table 2).

\subsection{Data analysis}

We moved from empirical data to grounded theory by shifting between emerging empirical themes and theoretical conceptualizations (Suddaby 2006). We used three main types of grounded theory coding procedures: initial, focused, and theoretical (Charmaz 2014). During initial coding, we attempted to understand our participants' views and (inter-)actions from their perspective. Whenever possible, we labeled our codes in our informants' own language to give voice to their views. To remain openminded and reflective, we used memo writing that included constructing maps and figures. Through several cycles reexamining initial codes, we generated first-order concepts (Van Maanen 1979) that captured our participants' experiences with and interpretations of their network engagement. For example, we categorized according to the descriptions of network meetings, collective actions, perceptions about network leadership, coordinators' functions and tasks, expectations toward coordinators', and participants' orientation toward and motivation for their network engagement.

Through focused coding, we sorted, synthesized, and categorized the large number of diverse initial codes. We compared participants' experiences, actions, and interpretations across interviews and observations. For example, we compared observations of events (different workshop meetings and its sub-events such as factory tours or informal talks, or procedures during the meetings, e.g. setting the agenda, delivering a protocol) at different times and places (network meetings taking place in different locations/member firms). We further compared our own understanding of observed processes and events with those of our participants, in particular, when they differ. As our analysis progressed, we increasingly used theoretical coding steps to build increasingly abstract categories with enriched explanatory power. We specified already revealed relationships between codes through coding for process, which involves conceptualizing relationships between experiences and events, and finding out what actions or conditions affected the occurrence of identified processes (Charmaz 2014). We were interested in how the observed network activity or process emerged (e.g. developing a concrete project, collective decision-making), and how the participants' emotions or actions (e.g. a member's expert input, way of organizing by coordinators) worked to construct and change such activities and processes. We were sensitive to the meanings that different participants attributed to these processes, how they talked about the network, and what they emphasized (e.g. rejection of status-differentiation and not granting leadership to individual members). We attempted to be cognizant of possible idealization of, or hidden, and taken for granted assumptions about 
Table 2 Description of data

\begin{tabular}{l} 
Data type and sources \\
\hline Literature \\
Research on interorganizational \\
networks and leadership, especially \\
on new forms of leadership \\
Research on identity and motivation \\
(individual- and collective-level \\
approaches)
\end{tabular}

Documents about our networks under study (BlueNet1, BlueNet2, RedNet) and two further networks (XNet and $\mathrm{YNet}^{\mathrm{a}}$ ): internal network reports about meetings, protocols of coordinating group meetings, promotional materials for network activities, newsletters, websites, publications, press handouts

Preliminary expert interviews: two key informants in double network roles (cf. below); five network coordinators

Informal dialogues: several network actors and coordinators during network meetings and conferences

Semi-structured interviews: six RedNet actors, three RedNet coordinators, three participants in double network roles (i.e., actor and coordinator in different networks), five BlueNet1 actors, two BlueNet1 coordinators, three BlueNet2 actors, two network weavers, and coordinators of $\mathrm{XNet}$ and $\mathrm{YNet}^{\mathrm{a}}$

Quantity and timeframe Use in knowledge generation process

Any number of articles and monographs

\section{Approximately 410 pages}

2009-2012

13 informal interviews (face-to-face and by phone $^{\mathrm{b}}$ )

Sept. 2009-Jan. 2011

\section{About 35 informal interviews (face-to- face)}

Sept. 2009-Nov. 2011

24 formal interviews,

30-75 min each

(13 face-to-face, 11 by phone; all recorded and fully transcribed)

Feb. 2010-Apr. 2011
Identifying research questions, problematizing theoretical and empirical challenges; reflecting on our own presuppositions, discussing research relevance, design, sampling, and methodological fit (groundwork phase)

Enhancing our theoretical sensitivity; shifting between empirically emerging themes and the literature to ultimately integrate our findings reflexively in existing relevant research (iterative cyclical coding phases)

Setting analysis; case selection (theoretical sampling); description of network initiation and development (esp. BlueNet1 and BlueNet2); developing a deeper understanding of the network context, as well as of emerging themes and critical incidents narrated in interviews, and observed during network meetings; facilitating discussions with participants

Making decisions about sampling strategies and case selection referring to networks, individual network actors, network meetings, as well as on the themes to be explored next

Deepening of our understanding of the network context, network-specific practices, activities, and objectives

Coded in iterative rounds on themes around network interactions, practices, and relationship development, network participants' expectations on coordination, network outcomes, influence processes, views about and expectations on network leadership; validation of emerging concepts from the participating observations

Focusing on emerging themes related to collective network leadership; developing the seven main themes and the core concept, collective network leadership identity 
Table 2 continued

\begin{tabular}{|c|c|c|}
\hline Data type and sources & Quantity and timeframe & Use in knowledge generation process \\
\hline 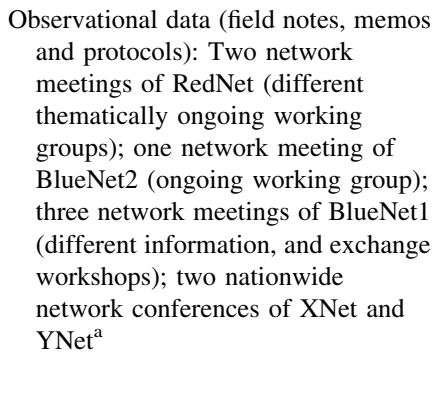 & $\begin{array}{l}25 \mathrm{~h} \text { formal } \\
\text { observations of } \\
\text { network meetings } \\
\text { Apr. 2010-Nov. } 2011 \\
14 \mathrm{~h} \text { informal } \\
\text { conference } \\
\text { observations (XNet, } \\
\text { YNet) } \\
\text { Sept. 2009; Oct. } 2010\end{array}$ & $\begin{array}{l}\text { Deepening our understanding of } \\
\text { network interactions (e.g., } \\
\text { cooperative and communicative } \\
\text { practices, collective decision, and } \\
\text { influence processes) in its natural } \\
\text { social setting; coded for the same } \\
\text { purpose like the interviews; } \\
\text { validation and refinement of } \\
\text { emerging concepts from the } \\
\text { interviews; motivating network } \\
\text { actors, and coordinators for } \\
\text { supporting our study }\end{array}$ \\
\hline $\begin{array}{l}\text { Feedback-dialogues: six participants } \\
\text { (in coordinators- and actors-roles; } \\
\text { BlueNet1, BlueNet } 2 \text {, and RedNet) }\end{array}$ & $\begin{array}{l}\text { Seven informal } \\
\text { interviews (five face- } \\
\text { to-face, two by } \\
\text { phone) } \\
\text { Apr. 2011-Apr. 2012; } \\
\text { March 2014; Oct. } \\
\text { 2015) }\end{array}$ & $\begin{array}{l}\text { Mirroring back results; figuring out to } \\
\text { what extent our emerging theory and } \\
\text { explanations make sense from our } \\
\text { participants' experience; reflections } \\
\text { on practical adequacy and possible } \\
\text { refinement of developed concepts }\end{array}$ \\
\hline
\end{tabular}

\begin{abstract}
${ }^{a}$ Although theoretically matching with our sample, XNet and YNet were not able to be included as complete network cases, because unfortunately we did not obtain adequate access to member firms. Yet, both network weavers and coordinators supported our study as interview partners

${ }^{\text {b}}$ The interviews were conducted partly over the phone, after we evaluated this procedure for our study's context. We did not perceive any negative effect on quality compared with face-to-face interviews; rather we had a very high rate of acceptance, easily gained our interviewees' confidence, and were able to be extremely flexible in considering our interviewees' high workload and needs
\end{abstract}

networks and network leadership. To understand the data at a more abstract level and to position it in the theoretical literature, we wrote memos about themes and emerging theoretical concepts. During theoretical coding, we further compared and integrated our memos and searched for relationships between categories and our emerging themes (cf. Charmaz et al. 2018; Charmaz 2014). We searched for theoretical concepts from the relevant literature that advance our understanding and might further develop our emerging categories, for example, defining variation within a category and specifying relations between categories, which represents a key idea of theoretical sampling (Charmaz 2014). That is, the grounded theory core principles of theoretical sampling and constant comparison that were introduced above were applied not only for choosing the network cases but also throughout the whole research process as we decided whom to interview next, what questions to ask, and which incidents, as reported in interviews, might be critical for our attention in subsequent observations.

Two of our participants, who held double network roles, also helped to provide a comparative perspective from their extensive experience in multiplex network engagements. Furthermore, our analysis benefited both from feedback from peers (i.e. from knowledgeable but detached colleagues) and from our interviewees, which enabled us to assess how our emerging theory made sense to our participants' 
experience. Our analysis was supported by a qualitative data software program that helped us in storing our data, and codes in a stable format, as well as search for overlapping themes or differences in the data. However, it neither provided tools for automatic coding nor eliminated paper and pencil from the coding procedures. Figure 1 shows our data structure and summarizes how we moved from first-order concepts to second-order categories and to the theoretically aggregated main themes (cf. Clark et al. 2010, who inspired the formal presentation of our data structure).

Given our methodological approach, it is neither possible nor intended to describe all aspects of the empirical context (Charmaz 2014; Suddaby 2006). Rather, and by using the grounded theory key concept of contrasting and comparing, we focused on emerging empirical main themes and grounded theoretical key differentiation features. Because it makes the analysis more concrete and explanatory, a comparative approach has been acknowledged to be particularly useful for advanced qualitative leadership theorizing (cf. e.g. Denis et al. 2012; Chreim 2015).

\section{Findings}

Following our grounded theory approach, we combined the results of our analysis (as depicted in Fig. 1) into a model that situates the emerging main themes with their relations in a more dynamic way (Fig. 2). A main result is the discovery of two network-specific identities - a task-based network identity and a joint-motivational network identity - that contribute to better understanding the emergence of the distinct (non)leadership phenomena that we found in our networks BlueNet and RedNet, which in other aspects were rather similar (see above).

In the following, we address each of our three research questions by drawing on the categories and main themes depicted in Figs. 1 and 2. Table 4 (Supplementary Appendix) offers additional representative supporting data for each second-order category.

\subsection{How and in what form, if at all, will leadership emerge in the networks?}

\subsubsection{No single leader emergence (BlueNet and RedNet)}

A foundational result is that no single individual emerged as a leader in either BlueNet or RedNet. Participants emphasized that some management or organization is a prerequisite for network functioning. However, participants did not see the individuals who engaged in such activities as "leaders". Rather, they found that coordinators and the executive unit carried out the business and were in charge of the network members:

"I wouldn't say that I feel myself being led by him. For me, he's a very pleasant moderator. ... But to ascribe a specific leadership role to the coordinator, it's not like that." 


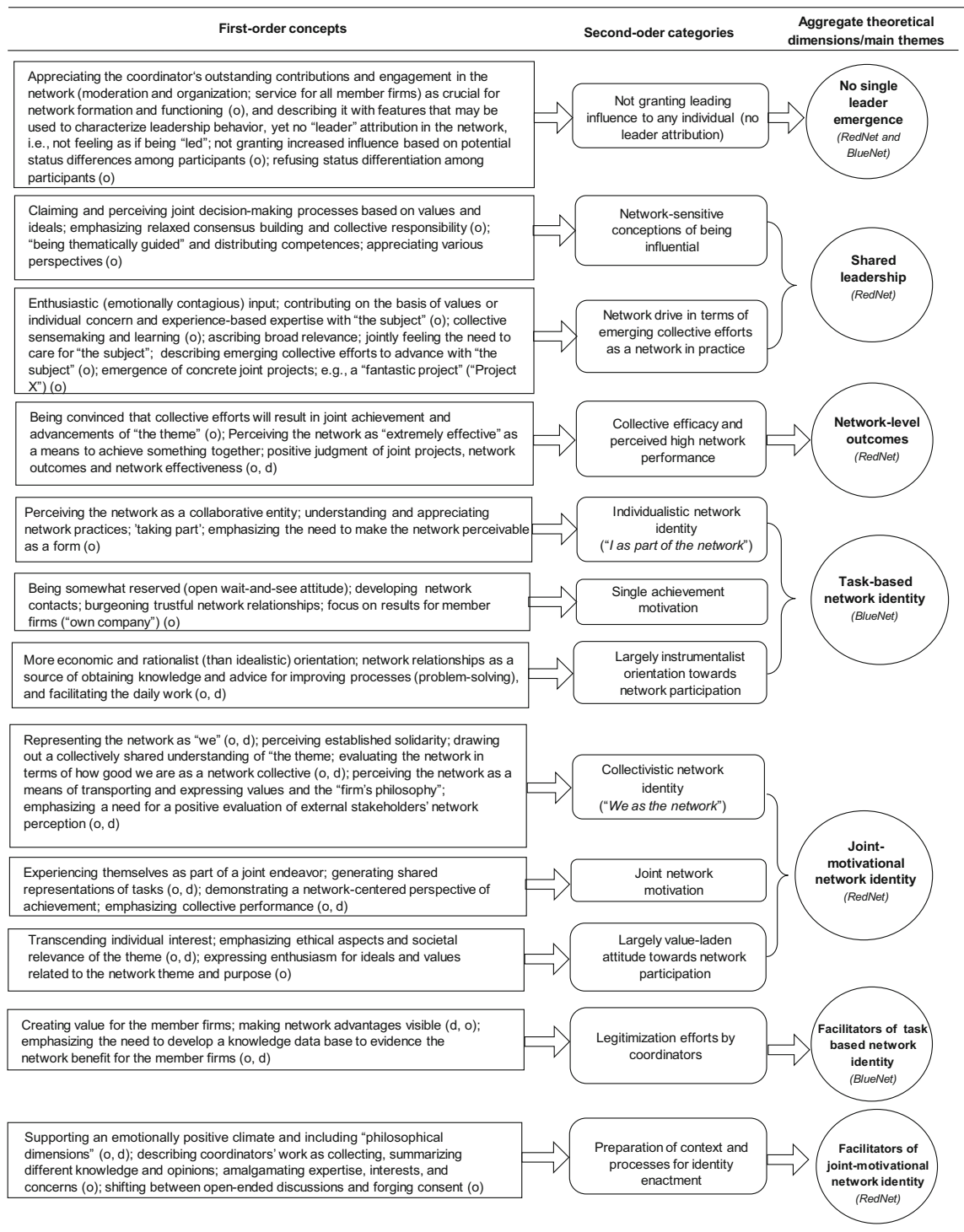

*All concepts are grounded on interviews; "(o)" indicates "supplement with observation"; "(d)" indicates supplement with documents

Fig. 1 Data structure

Also with regard to the relations among the participants, they did not see the need to be led:

"[In the network] it's not about companies or participants having to be specially led. And they don't want that either... This is why opinion leadership is not essential in this area. Communication is. It's about acquiring security, 


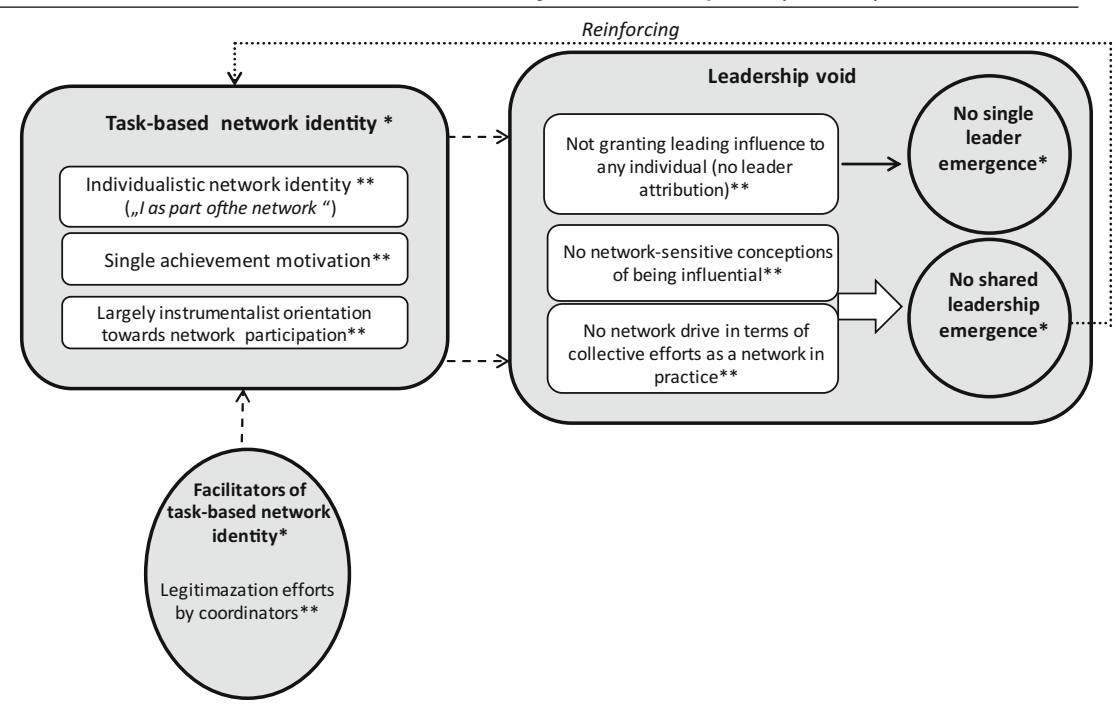

Joint-motivational network identity and Shared Network Leadership Development (RedNet)

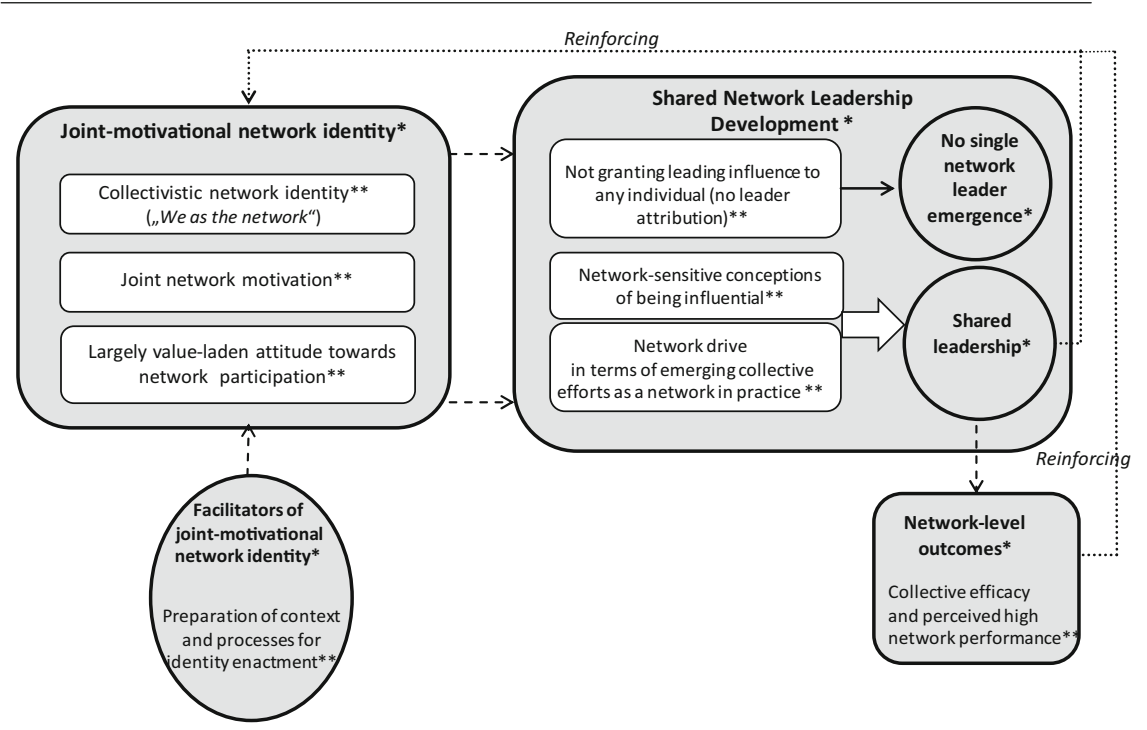

* Main themes

** Second order categories, focusing on identified main network differentiation features

Fig. 2 Alternative models of (non-)leadership development and network identity

acquiring self-assurance; are we doing this right? ...It's not about someone being the opinion leader."

That is, not even "opinion leadership" was viewed as being useful, because the purpose of the network was learning based on intensive experience exchange. 
Participants claimed decision-making autonomy and rejected the notion that a single individual may have a specific influence on the other participants. Our data showed that network actors felt no pressure to agree with suggestions that other participants might make and clearly rejected the potential hidden attempts of other participants to influence them. Our interviewees often emphasized that the differentiation between leader and the led is not really easily applicable. They fundamentally questioned the notion of "leadership":

"It can certainly happen that someone, for some reason or other, has the credentials for preparing the subject better. So he'll probably be commissioned to do it because he simply stands out objectively. But that should be it.... This has nothing to do with him then having a different status to the other participants.... It's not about having power in some way as a member; it's about processing topics.... This doesn't have all that much to do with leadership."

As we learned from our participants, social acceptance of a special status was missing. That is, status differentiation as a possible source of influence and related leader emergence lost its significance in the networks. Overall, we found that participants rejected the notion of leadership by other participants or coordinators. They did not grant a leading influence to any individual, and in practice, no leaderfollower relationships were established.

\subsubsection{Shared leadership (RedNet only)}

Network-sensitive conceptions of being influential represent the first second-order category for conceptualizing shared leadership in the networks. Our interviewees articulated problems with the use of terms such as leadership, leaders, and followership in relation to the network, and they searched for adequate wording. Regarding the coordinator's work, one RedNet actor observed, "no one expects that he will provide concept input off his own bat, draw up, or contribute preconceived concepts... What it is, is that we do this, and, with him, he only targets something, in quotes." Similarly, this RedNet actor emphasized the community-based nature of decisions: "Well, we're the decision makers, so we determine the topics as well... because RedNet, the organization, can't do that-the members do that." Many participants explicitly held this opinion. They described decision making at an inclusive network level and noted the attempt to find a "common denominator", and that "people look for consensus in the network." However, one important point was the concurrent emphasis that it is not always expected that consensus will be achieved. Because no one feels a compulsion to agree to specific suggestions or intended projects, network participants developed a rather relaxed attitude toward consensus finding. Hence, negotiating - an important and well-known mode of interaction in organizations or groups - was not so much required. Rather, features of the primary mode of interaction are open exchange, interested listening to other participants, and reflections on what could be learned from the experience of other participants are. In describing their network involvement, participants emphasized voluntariness, autonomy, self-responsibility, and that all participants have the same 
rights and opportunities within their network. Other RedNet actors developed the notion that leadership is "spread over many shoulders", that "there are no leaders. There are only competencies that are distributed and that are carried out in certain circumstances by specific persons", and that the participants "are all thematically guided somehow." Another RedNet actor related this to the notion of subject responsibility:

"In the network it's the companies, who have subject responsibility... Their responsibility is to contribute subjects. And they are also responsible for the process being open... subject responsibility also means that when inquiries come later on, it's possible to turn to this person."

Hence, subject responsibility involves a kind of relational responsibility and the willingness to provide support. How the network-sensitive conceptions of being influential described above are transformed into concrete collective practices is described next.

Network drive in terms of emerging collective efforts as a network in practice captures the interaction dynamics and practices of emerging shared leadership. For example, we were able to show how far expert input or contribution by a participant leads to collective processes that prepare the ground for shared leadership: First, it should be based on traceable practical experience, which in addition must be convincingly based on the developments that participants experienced as entrepreneurs. Second, the contribution or input had to be widely emotionally contagious based on the perception of collectively shared concerns:

"Well, [we take up a suggestion] if it concerns the very latest subjects, where people say what really affects us all, where we simply feel that the need is there to look further into the subject."

Overall, our data revealed this to be the case when a single participant's experience-based expert input resonated with other members' value orientation, ideals, and concerns. As an example, "Project X" was a concrete network project through which such a confluence of members' orientation, ideals, and concerns became apparent as the project quickly became a "fantastic" new project of "societal relevance" that they "all" wanted to pursue. This project emerged from interaction among network participants and was driven by the described emotional involvement and a kind of collective willpower. As one RedNet coordinator observed, some of the network members introduced subject $X$ and all of the participants said, "Ok, we must be the pioneers with subject X". One of the network coordinators described how the members developed conjoint efforts, and that "the focus was no longer on the development of individual companies [but on] what concerns all of them." This participant explained:

"We then discussed the rest and then said that we could definitely do something there. ... We soon reached the decision that there simply has to be a new platform. ... And this major project was created from this working group... They were all really hooked on this subject." 
Another participant observed, "We all knew we wanted to work on this subject." He went on describe how joint efforts were undertaken to initiate a new group for "Project X". The participants felt "very enthusiastic about this subject" based on collectively shared concerns. They were affected, wanted to pursue this subject collectively, and developed a joint volition that resulted in their concerted efforts. In this way, the network as a collective was mobilized for concrete joint action. We conceptualized these processes as "network drive" that metaphorically captured the evolving enthusiasm and collective efforts of the network as a whole. Network participants became engaged in making things happen collectively based on joint volition and, in essence, became involved in collective network level influence processes (i.e. the network as a whole), and thus enacted shared leadership.

\subsubsection{Network-level outcomes (RedNet only)}

The described shared leadership dynamics in RedNet were related to network-level outcomes in terms of collective efficacy and perceived high network performance. RedNet participants repeatedly articulated positive judgments on achieved network outcomes and overall network effectiveness. With regard to intended and actually achieved results, our data showed that-in contrast to BlueNet-the results in RedNet are intended to be achieved for the entire network. That is, although RedNet naturally serves the improvement of member organizations' performance, participants intended to advance with themes and projects through a common performance as a network. We saw that RedNet actors were full of confidence about being successful with their emerging new project and that they perceived their network activities as being very successful. They were convinced that collective efforts will result in joint achievement and advancement of "the theme". Many RedNet actors referred to their network as being "extremely effective" as a means to achieve something together. Concrete outcomes became manifest, for example in the form of "petitions" that achieved improvements for subjects that were "really existential for us all". Overall, they referred in particular to the influence that the network had on politics and the public (e.g. lobbying), and they reported outcomes such as evaluating joint strategies, or effectively submitting petitions or common statements, to direct public opinion or legal regulations.

\subsection{What might contribute to explain these different (non-)leadership phenomena?}

\section{Task-based versus joint-motivational network identity}

The core network phenomenon that contributes to better understanding the described different leadership development is network identity. It emerged in a distinct manner in our networks, which were rather similar with regard to other aspects (e.g. overall purpose, general network structure, cf. Table 1). As illustrated in Fig. 2, two different identities emerged: a task-based network identity (BlueNet) and a joint-motivational network identity (RedNet). Table 3 summarizes the key 
Table 3 Task-based vs. joint-motivational network identity: key differentiation features, and representative supporting interview quotations

\begin{tabular}{|c|c|c|c|}
\hline \multicolumn{2}{|l|}{ BlueNet } & \multicolumn{2}{|l|}{ RedNet } \\
\hline \multicolumn{2}{|c|}{ Task-based network identity ${ }^{\mathrm{a}}$} & \multicolumn{2}{|c|}{ Joint-motivational network identity ${ }^{\mathrm{a}}$} \\
\hline $\begin{array}{l}\text { Components } \\
\text { (second-order } \\
\text { categories) }\end{array}$ & Representative quotations & $\begin{array}{l}\text { Components } \\
\text { (second-order } \\
\text { categories) }\end{array}$ & Representative quotations \\
\hline $\begin{array}{l}\text { Individualistic } \\
\text { network identity }\end{array}$ & $\begin{array}{l}\text { I can say I'll join in and take } \\
\text { part" } \\
\text { "It's exchanging information } \\
\text { and ideas with specialists } \\
\text { from other companies, other } \\
\text { divisions" }\end{array}$ & $\begin{array}{c}\text { Collectivistic } \\
\text { network } \\
\text { identity }\end{array}$ & $\begin{array}{l}\text { "We are a large community" } \\
\text { "Our theme [environmental } \\
\text { management and protection] } \\
\text { also is a societal concern" }\end{array}$ \\
\hline $\begin{array}{l}\text { Single } \\
\text { achievement } \\
\text { motivation }\end{array}$ & $\begin{array}{l}\text { "Then you try to apply it [new } \\
\text { ideas] in your own } \\
\text { company" } \\
\text { "Everybody says, I'll only do } \\
\text { that if it's interesting for me, } \\
\text { I do my thing" }\end{array}$ & $\begin{array}{c}\text { Joint network } \\
\text { motivation }\end{array}$ & $\begin{array}{l}\text { "So you support the others } \\
\text { even if your own company } \\
\text { isn't directly affected now } \\
\text {... It was a case of help for } \\
\text { all those in the RedNet" } \\
\text { "In the network I'm } \\
\text { motivated, I want to achieve } \\
\text { something jointly with the } \\
\text { others... what do we all } \\
\text { want" }\end{array}$ \\
\hline $\begin{array}{l}\text { Largely } \\
\text { instrumentalist } \\
\text { orientation } \\
\text { towards network } \\
\text { participation }\end{array}$ & $\begin{array}{l}\text { "The information was very } \\
\text { useful, because we do not } \\
\text { have very much experience } \\
\text { in environmental } \\
\text { management. In some } \\
\text { cases, our customers came } \\
\text { to us and asked if we } \\
\text { already had a certification } \\
\text { in environmental } \\
\text { management" }\end{array}$ & $\begin{array}{l}\text { Largely value- } \\
\text { laden attitude } \\
\text { towards } \\
\text { network } \\
\text { participation }\end{array}$ & $\begin{array}{l}\text { "There's much less pure } \\
\text { egoism here,... You can } \\
\text { feel a certain idealism" } \\
\text { "We want to achieve } \\
\text { something reasonable... It's } \\
\text { not about making money in } \\
\text { the first place" }\end{array}$ \\
\hline
\end{tabular}

\footnotetext{
$\overline{{ }^{a} \text { All categories are not grounded solely in interview data but also in data from observations and docu- }}$ ments (cf. Fig. 1)
}

differentiation features of BlueNet's and RedNet's network identity and provides representative illustrative interview quotations.

As our data showed, BlueNet members' task-based network identity involves "individualistic network identity", "single achievement motivation", and "largely instrumentalist orientation towards network participation" (see Table 3, Figs. 1, 2). BlueNet members appreciated the open, respectful exchange on an equal footing in the meetings. Participants perceived their network as a collaborative entity, and thus developed an understanding of the network purpose. In part, however, a kind of wait-and-see orientation dominated the meetings. The following quote sheds light on how many of the BlueNet participants perceived and appreciated the collaboration in the workshop. 
"A subject is discussed, everything is discussed intensively, but there's no conclusion [in contrast to usual meetings that I'm familiar with in the company] ... Or, what goes beyond this [beyond the actual meetings of workgroups], ... And then the participants exchange opinions. Where someone starts by asking ... Have you got any experience here? This is a group that I trust, where I know that can ask questions. That you just develop a network."

BlueNet members often emphasized that they enjoyed taking part in the meetings because they can find out what other specialists think, and because they can use this for their own work in their companies. Hence, they focused on results for their "own company" — an attitude that points to a single achievement motivation. The largely instrumentalist orientation towards network participation, for example, appears from the fact that obviously only external pressure provided the motivation for using environmental management systems (cf. Table 3). Overall, the BlueNet members' orientation toward network participation tended to be economic and rationalist (rather than idealistic), and primarily directed to achieving results for member firms only. Moreover, the BlueNet participants' dominant perception of their network engagement was a "taking part" attitude that was related to the perception of "I as part of the network" (cf. Figure 1). This more of an entity view, which separates the individual member and the network as a whole, was a main feature of the BlueNet members' individualistic network identity.

In contrast, RedNet members perceived themselves as part of a joint endeavor and displayed "collectivistic network identity", "joint network motivation", and a "largely value-laden attitude towards network participation" (see Table 3, Figs. 1, 2). A subtle clue that revealed the member organizations' collectivistic identity was the tendency to refer to themselves as "we." Because RedNet members developed a clear understanding about their common network purpose, they demonstrated a well-evaluated agreement on basic network positions in terms of self-commitment laid down in a "code of behavior, in which specific directions are stipulated, with regard to our subjects," as one RedNet actor recalled. The participants' agreement and shared understanding of overarching "subjects" was evident in their references to the subject in terms of an understanding of this theme that is taken for granted and of what the network stands for. In addition, they used the term "our subject," indicating that RedNet members perceived themselves as a "large community", bound together through their common concerns. RedNet actors metaphorically described their common ground and respective interdependencies: "We're all in the same boat." This "we feeling" accompanied the perception of increased solidarity. Concurrently, the network provided a platform "to bring our philosophy out externally much better through the network work," as this RedNet actor stated. As we saw, the network became a means to transport values and express a specific identity for the members. On this basis, the members evaluated their network in terms of "how good we are as a collective." Overall, they perceived RedNet as "a very good network" and that it is successful in transporting members' values and philosophy (e.g. on environment management and sustainability). 
Joint network motivation - the second component of RedNet's identity means to be collectively motivated for common achievement and involves perceiving themselves as part of a joint endeavor. Hence, joint motivation is a collective level phenomenon: It captures the notion that the collective wants something and is motivated to achieve conjointly as a network. One indication that pointed to joint motivation was the frequent use of the phrase "we want" (e.g. "we want to promote"; "we want to see"). One participant emphasized that they wanted to pursue their concerns through joint endeavors in terms of "just the way we're used to: network building, joint work on a joint subject and joint development of instruments and methods." Another interviewee stated that the intention in publishing the yearbook (in terms of a documentation of the network's activities, achievements, and purpose) was to develop a joint performance: “... but then really as joint companies, I mean in a joint performance and not each one for itself." Thus, our interviewees were highly motivated to do something together, as the representative quotation in Table 3 shows. This attitude was related to the rejection of potential attempts to pursue micro-political or particularistic goals. As this participant recalled:

"What an individual wants, well, he can do that at home. And in the network, when people arrive at a common motive, they try to realize it."

Thus, a fundamental logic behind these observations was the motivation to develop something collectively, as one RedNet actor's quote showed: "In RedNet it's all about growing something together." In essence, our data showed that the actors perceived themselves as part of a joint endeavor. The competing environment was not seen as providing opportunities for joint achievement outside of the network. Further, we found an overall positive orientation toward the network in terms of a largely value-laden attitude towards network participation, which represents the third component of joint motivational network identity. The underlying attitude towards network participation went beyond an instrumentalist orientation. RedNet participants showed a significant commitment to the network theme. They were interested in doing something together, and they transcended single interests. The collective engagement was largely based on the conviction to do "something reasonable", and many participants emphasized ideals and values, and thus were not guided by economic and shareholder value in the first place, as the representative quotation in Table 3 illustrates. Network members were fundamentally interested in value-related and ethical themes, as this interviewee noted:

"We make sure that we always invite speakers who work through the topic in depth. I mean, that you take this step into the world behind the material. That you include philosophical and moral topics as well."

Many participants illustrated this topic by reporting on an enthusiastic engagement for value-laden, concrete projects (e.g. fair trade) and that were considered to have a certain "societal relevance" (e.g. ecological thinking and sustainable development). This focus on the common good, or at least the welfare of the greater collective, emerged as a core motive for establishing network relationships rather than building intensive dyadic cooperation among the members. 


\subsection{What are significant differentiation features in the network coordinators' main activities that might contribute to facilitating emerging different (non)leadership phenomena in BlueNet and RedNet?}

\section{Facilitators of task-based vs. joint-motivational network identity}

The key differentiation feature in the network coordinators' role and practices relates to the way in which they shape their members' network identity. It should be noted that - in line with our methodological approach-it is neither our intention nor is it necessary to provide a description of the whole set of functions and practices that are necessary for ensuring the networks' functioning (e.g. general administrative tasks). Rather, we focus on the functions and practices that were related to the emerging leadership themes and identity pattern (i.e. either the development of a task-based identity or a joint-motivational identity). As depicted in Fig. 1, in BlueNet the coordinators' particular main practices were guided by legitimization efforts. This involves creating concrete (practical) value for member firms to make these network advantages visible to the member organizations. Such practices were considered as key facilitators of the members' task-based network identity. BlueNet participants emphasized, for example, the need to develop a knowledge data base (e.g. on the basis of "worksheets", which were regarded as very useful for working on potential or actual existing problems) to evidence the network benefit for member firms and to justify network participation. Further, the BlueNet coordinators stressed the importance of making the network as such perceivable for their members by developing a corporate identity (e.g. a network $\log$ ).

In contrast, RedNet coordinators' activities facilitated joint-motivational network identity by the preparation of context and processes for identity enactment (cf. Fig. 1). This involves an inclusive, open-minded, and heedful moderation without "prefabricated opinions" to give "everyone an opportunity to keep up", and "to meet people halfway as well" (RedNet actor).The coordinators summarized different knowledge and meanings, promoted collective sense making, and were engaged in sense giving in that, for example, they tried to show "cross-connections" of subjects, or provided input from an overarching perspective. However, such inputs were provided more as consultation than as compulsion, as this coordinator recalled: "Often a vote isn't taken; there's more of a formation of opinion." The coordinators noted that they tried to include space for identity expression and forged the network as an identity enactment scene to support the emergence of collectively shared stories and ideals. In doing so, coordinators sensibly shifted between moderating open-ended, collective learning processes and forging consent or decision-making. Interestingly, however, decisions were usually not made through a democratic vote, as observed by this coordinator: "Voting by show of hands is very rare." Rather, to capture emerging consent or still existing diverging individual opinions, the coordinator relies on the perceived mood or atmosphere: "It's more of a feeling if we've addressed a topic, discussed it. There is an unspoken consensus, accordance, without things having to be voted on." In the meetings, the coordinator 
looked around the group, made eye contact with those present, and attempted to capture the mood to extract a line that allowed him to continue his work. Overall, the coordinators' practices were related to expert knowledge and relational skills, such as mindful listening and sensitivity to the mood within network settings. Given the crucial tasks of coordinators, it became apparent that networks were not "selforganizing". As one coordinator reported, he often thought about a stronger form of "self-organization", but also realized that such an approach would not work-an observation that he also reflected and confirmed in the feedback dialogue. Finally, a pleasant ambiance and an emotionally positive climate appeared to be relevant, as for example this interviewee observed: "Everything was combined with a certain amount of cheerfulness and ease." Another participant saw the positive climate of cooperation as stemming partly from "this step into the world behind the material, that you include philosophical and moral topics as well," and finally noted, "In the RedNet, we have a philosophical component as well."

\section{Discussion}

A major contribution of our study is the development of a grounded theoretical model that comprises the following main findings (see Fig. 2): Distinct pattern of network participation mainly characterized by either a task-based network identity - composed of an individualistic network identity, a single achievement motivation, and a largely instrumentalist orientation towards network participation-or a joint-motivational network identity-composed of a collectivistic network identity, joint network motivation, and a largely value-laden attitude towards network participation-is related to distinct (non)leadership phenomena in our networks. Our findings suggest that a task-based network identity is related to a leadership void (i.e. no single participant emerged as a leader, nor did the collective become engaged in leadership processes), whereas a joint-motivational network identity is related to shared leadership (i.e. the members developed alternative network-sensitive conceptions of being influential as well as network drive in terms of collective efforts in practice). Further, we found that network coordinators are relevant by providing support for leadership development-however, not in terms of traditional leadership, but in a more indirect and subtle preparation of context and processes, considering identity-related issues, in particular.

Our study's findings contribute to the following main fields: first, we advance understanding of (non)leadership phenomena in collaborative interorganizational networks, a phenomenon that up to now has been little understood. Beyond that, and in keeping with our interpretive grounded theory approach, we seek to relate our study's findings to matching theory, and to sketch out how far our grounded theoretical concepts advance corresponding theory. In our case, shared leadership emerged empirically. Therefore, second, we were able to advance theory on plural forms of leadership such as collective or shared leadership. We shed new light on the generative mechanism of shared leadership by revealing the relevance of jointmotivational network identity as an energizing source of shared leadership development. Further, we offer conceptual progress on how to distinguish jointly 
constructed shared leadership processes from other collective-level phenomena (e.g. team cooperation or system-wide organizing processes).

\subsection{Advancing understanding of (non)leadership phenomena in collaborative interorganizational networks}

Our findings contribute to better understanding of leadership phenomena in collaborative interorganizational networks, in particular concerning leadership at the neglected (interpersonal) interaction level without disregarding relevant conditions related to the network level (e.g. Huxham and Vangen 2000; Feyerherm 1994; Denis et al. 2001; Ospina and Saz-Carranza 2010; Weibler and Rohn-Endres 2010; Miles et al. 2010; Müller-Seitz 2012; cf. our literature review). An initial finding of our fieldwork is that the networks either developed shared leadership or cooperated "leaderless" (i.e. established a leadership void). Our fieldwork shows that embeddedness in a peer-like work setting based on the lack of a priori existing formal guidance structures may significantly affect participants' views on how to be influential and how to "lead" or "be led" in such a way that single leader emergence - in terms of direct or individual leadership - is thwarted in all of our network cases. For example, we found a sense of network embeddedness among the participants that involved rejection of status differentiation. Regarding leadership, this means that even an individual's potential higher status was not seen as providing the source of accepted influence necessary to grant leadership to such an individual. These findings are striking and counterintuitive, because it might be expected that a person who-for good reason, such as significant expertise and engagement- "stands out objectively" (as emphasized by a network participant), would emerge as a leader (Stone and Cooper 2009). Indeed, general research on leader emergence showed that an individual emerges as a leader based on "credits" ascribed to him or her by the other group members, for example, the individual's high competence or outstanding contribution to the achievement of group goals (e.g. Hollander 1974; Stone and Cooper 2009 for an overview). In contrast, our work shows that this is not the case and suggests that organizational contexts actually exist in which participants, such as those in our networks, successfully strive to maintain the informal peer-like setting, and collaborate in a way that no single individual is granted a leading influence.

Our study concretizes this phenomenon by adding that networks are not necessarily "leaderless" or a "leadership-free zone". Rather, leadership is vitally needed; however, it emerged only in the collective form. Our fieldwork showed that, given embeddedness in a peer-like networked context, participants developed context-sensitive alternative (i.e. non-individualistic and more relational) conceptions of being influential, which-under certain circumstances (as described in our model) - led to collective efforts by the network as a whole (i.e. network drive and shared leadership development). These aspects of our findings echo the relevance of plural leadership forms, such as collective or shared leadership, in collaborative interorganizational networks (Denis et al. 2001; Huxham and Vangen 2000; Ospina and Saz-Carranza 2010; Weibler and Rohn-Endres 2010; White et al. 2016). 
Moreover, we have identified distinct types of network identity as a significant condition for the emergence of the observed different network leadership phenomena. As described in our model, a task-based network identity is related to a leadership void, whereas joint-motivational network identity is related to shared leadership development. Since identity emerged as a key concept for better understanding network leadership phenomena in our context, we draw on literature on identity and developed two network-specific identity conceptions. Before we continue to discuss our theoretical contribution in this regard, we provide information on the concept of identity relevant for our study's context and contribution.

In keeping with our social constructionist leadership approach, we subscribe to an understanding of identities as socially constructed phenomena that are dynamic and fluid in nature (Ashforth et al. 2008, 2011; Gioia et al. 2013). In line with Ashforth et al. (2008: 327), we refer to identity as "a self-referential description that provides contextually appropriate answers to the question" Who am I as individual? (individual identity) or Who are we as organization? (organizational identity) (Ashforth et al. 2008; Corley et al. 2006). According to Corley et al. (2006: 87), organizational identity refers to a "self-referential meaning where the self is the collective" comprising self-definition, values, and affect as its core. From a social constructionist perspective, an organizational identity is seen as being defined by the members of an organization "to articulate who they are as an organization" and, thus, primarily involves "the labels and meanings that members use to describe themselves and their core attributes" (Gioia et al. 2013: 127). In our study's context, the network's identity also involves a collective-level motivational concept (i.e., "joint motivation" as contrasted with "single achievement motivation"). We, therefore, labelled this newly developed identity concept a "joint-motivational network identity".

Our study inductively linked a collective or network level identity (i.e. in terms of an identity held by the network; cf. Corley et al. 2006; Ashforth et al. 2011) with (collective) leadership emergence. In contrast, research on leadership identity still focuses on the individual level of identity (i.e. in terms of an identity held by an individual). A leader identity can be defined as a "sub-component of one's identity that relates to being a leader or how one thinks of oneself as a leader" (Day and Harrison 2007: 365; cf. Epitropaki et al. 2017). Because of the emerging networkspecific nature of the identity constructions found in our investigation, we add to this understanding the notion of leader-and-follower identities as contextualized phenomena emerging from social interaction processes (Collinson 2006; DeRue and Ashford 2010). However, even this interaction-oriented leader-identity perspective usually conceptualizes single leader emergence (i.e. the development of either a leader or a follower identity). In this context, leadership identity researchers traditionally emphasize that (effective) leadership emergence requires clear role differentiation and clarity in individuals' identities as leader and follower. For example, DeRue and Ashford (2010) highlight that strong and effective leaderfollower relationships imply that there is clarity in the individuals' identities as leader and follower. They describe a process by which individuals jointly co-create their respective identities as leaders and followers-via processes of claiming and 
granting leadership among each other-and thereby construct a leadership relationship. Overall, and although considering relevant dynamics of the social construction of leadership, they remain at the individual-level of identity as the source of leadership, in that they focused on the differentiation of either a leader or a follower identity. Similarly, Lindgren and Packendorff (2011) referred to individual-level identity concepts when studying the emergence of shared leadership.

Hence, even when plural forms of leadership are studied, such as collective or shared leadership, existing leadership identity approaches neglect organizational or collective level identity conceptions (i.e. in terms of an identity hold by an organization or network) as a (potential) source of leadership emergence (cf. Epitropaki et al. 2017). That is, existing leadership identity approaches usually do not consider the possibility that neither a leader nor a follower identity will emerge. Hence, DeRue and Ashford (2010: 642) finally called for further research on leadership identity that extends their work "by considering the process [of identity construction] at the group level" and on what happens when "less emergence of a well-defined leadership identity" might probably occur in certain contexts. This is indeed what we empirically found in our contexts, in that our data did not bear out an identity differentiation between leader and follower. Moreover, we were able to move beyond that by revealing that the network participants developed a jointmotivational network identity. This network-identity fueled the cultivation of alternative conceptions and practices of being influential as a network collective. On this basis, network participants developed network drive in terms of collective efforts and thus finally enacted shared leadership. Overall, we advance the study on collaborative interorganizational networks by elucidating relevant network internal functioning mechanisms related to (non)leadership phenomena, and in particular by revealing the collective nature of network leadership, and the joint-motivational network identity-based energizing source of its emergence.

\subsection{Advancing theory on plural leadership forms such as collective or shared leadership}

Collaborative interorganizational networks have recently been considered to be particularly fruitful contexts for examining emerging shared leadership — not at least given their lack of formally (a priori given) guidance structures. For example, Sergi et al. (2012) argued that these settings provide "fertile grounds for exploring the ins and outs of collectivistic approaches of leadership" (2012: 406; cf. Denis et al. 2012; Endres and Weibler 2017). Since, in our context, shared leadership processes emerged empirically, we draw on literature on shared leadership study and relate our emerging findings to this field. Shared leadership is a plural form of leadership which involves leadership being collectively shared among different people, and constructed in interaction (Avolio et al. 2009; Denis et al. 2012; Nicolaides et al. 2014). Shared leadership fundamentally has been defined as "an emergent state where team members collectively lead each other" (Avolio et al. 2009: 431; cf. Pearce and Conger 2003; Day et al. 2004). Hence, shared leadership may not be localized in any individual who conducts a superior role; rather it is a collectivelevel phenomenon which is embedded in a web of dynamic relationships (Avolio 
et al. 2009; Endres and Weibler 2017; Fitzsimons et al. 2011). Shared leadership (and related plural leadership forms such as collective and distributed leadership) is among the most momentous emerging themes in leadership research (cf. for recent overviews Denis et al. 2012; Fitzsimons et al. 2011; Dust and Ziegert 2016; Nicolaides et al. 2014; Endres and Weibler 2017). Given these instructive overviews, the discussion on the various forms and perspectives is not repeated here. Instead, and in keeping with our methodological/paradigmatic foundation, we draw on perspectives of shared leadership that study leadership as socially constructed through interactions, and as embedded in a web of relationships and context (Endres and Weibler 2017; Sergi et al. 2012; Fitzsimons et al. 2011; UhlBien 2006; Hosking 1988 cf. our theory section). Pursuant to extant literature, we use the terms shared leadership — as characterized above—and collective leadership interchangeably (cf. Avolio et al. 2009: 431; Nicolaides et al. 2014); however, we point to their socially constructed and relational basis (Endres and Weibler 2017; Fitzsimons et al. 2011; Sergi et al. 2012).

Despite the considerable amount of insightful contributions, a key problem in shared leadership study is still how to grasp and conceptualize emerging shared leadership processes that are embedded in interaction and relationship dynamics among individuals, and thus on how to distinguish such plural leadership forms from other interaction related collective level dynamics, such as cooperative teamwork or similar (Denis et al. 2012; Endres and Weibler 2017; Sergi et al. 2012; Crevani et al. 2010). Hence there is a need to better understand how shared leadership actually occurs. Therefore, Endres and Weibler (2017: 231) called for "more explorative studies that approach leadership phenomena inductively, and thus do not start with 'leadership' or what is assumed to be leadership, but rather with interaction dynamics and practices as they occur in a specific setting", in particular, when trying to study plural forms of leadership. That is, the emergence of those demanding collective level leadership forms should be empirically evidenced. Based on their critical interpretive synthesis of research on social constructionist leadership, Endres and Weibler (2017) argue that the consideration of influence processes in terms of leadership manifestation may help to reduce the risk of diluting the distinctiveness of leadership. Basically, this means, conceptualizing a phenomenon as leadership involves the identification of emerging flows of influence processes at either the interpersonal or collective level (or both). This, however, is particularly challenging for the collective level, i.e. for identifying shared leadership phenomenon, a constellation in which no single individual is identifiable as the source of influence, rather the collective is. Hence, a key question is how to make such elusive dynamics such as emerging (informal and collective) leadership tangible if no single individual's influence emerges as network leadership (Blom and Alvesson 2015; Denis et al. 2012). For that reason, in order to qualify general collective interaction related dynamics as leadership, in place of (traditional) individual level influence components, collective level components are needed to capture a collective's influence and to understand the generative mechanism of its emergence. We address both of these problems. Our emerging concepts' main contribution here is twofold: first, the cultivation and enactment of networksensitive conceptions of being influential, and in particular the finally emerging 
concept of network drive in terms of collective efforts as a network, capture the influence component at the collective level in place of the missing leadershiprelated influence activities from single individuals. These emerging flows of influence represent the collective "leadership manifestation", which is a conceptual prerequisite for collective or shared leadership (Endres and Weibler 2017: 222). Second, joint-motivational network identity with its components collectivistic network identity, a largely value-laden attitude towards network participation, and joint network motivation, captures the underlying energizing source of shared leadership development. On the basis of our study's findings, we offer advancements in a more precise theoretical framing and study of plural leadership forms, such as collective or shared leadership, than existing literature has done (e.g. Crevani et al. 2010; Lindgren and Packendorff 2011; Huxham and Vangen 2000; Denis et al. 2012). We suggest setting a high bar for conceptualizing collective phenomena in terms of shared or collective leadership (cf. Endres and Weibler 2017; Sergi et al. 2012; Blom and Alvesson 2015) — that is, to identify collective level influence processes and the joint-motivational identity-based (energizing) source of its emergence in the respective context. This implies taking the nonemergence of leadership more seriously into consideration. Our study provides a rich description of, and new insight into, non-leadership (i.e. a leadership void in one of our networks in which no single participant emerged as a leader, nor did the collective become engaged in leadership processes). Therefore, our findings echo the relevance of non-leadership phenomena for understanding leadership in contemporary organizations more comprehensively (cf. Alvesson and Sveningsson 2003; Alvesson and Spicer 2012; Blom and Alvesson 2015; Chreim 2015).

\subsection{Practical implications}

Collaborative interorganizational networks provide a challenging context for "leaders" in traditional terms, since single leadership_as the still dominant and widely spread leadership understanding in the business and organization contextobviously seems not to be the way of leadership that fits into this context. This applies even despite the finding that leadership is called for and considered as crucial for fruitful forms of network participation. Our findings suggest that network coordinators or individuals with similar roles should understand that, in the network context, participants feel significant, yet sometimes implicit, aversions against single leadership (e.g. based on the observation that status differentiation is rejected) and, more importantly, that the networks probably either develop shared leadership or established a leadership void (i.e. cooperated leaderless). Hence, network coordinators or managers should accept being sidelined, whereas network participants as a collective clearly gain center stage, and may develop shared leadership. However, this will occur only under certain circumstances, which relate to the described identity-based energizing source of its emergence. Our study's findings suggest that the revealed processes of shared leadership development are neither self-organizing nor another type of self-leadership. We argue that shared leadership may be fostered through a context-sensitive influence on members' network identity. For example, network identity-related processes may be forged in a way 
that they may transcend members' perception of "I as part of the network" and develop a sense of "we as a network" (i.e. in terms of a joint-motivational network identity). This implies, for example, moving beyond evidencing the benefits of the network for the members in a dominant instrumentalist way (cf. the BlueNet case). Rather, coordinators should consider becoming engaged in creating a kind of open space in terms of an identity enactment scene, which allows exploring commonly held and identity enhancing ideals and values (cf. Wellman 2017; Kourti 2017). To create such a space, it is important to understand-besides meeting the structural and administrative requirements for network functioning - that interactions must be nourished to acquire the adequate dynamics within networks (cf. Larson and Wikström 2007). This implies maintaining an informal atmosphere to forge an open and unbiased exchange that is respectful and non-judgmental, and that may ease emotional expression, and to move beyond a rational and pure instrumentalist attitude towards the network. Our study's findings concerning the importance of an informal atmosphere without status differentiation echo recent theorizing by Wellman (2017: 612), who, for example, suggests that "downplaying formal job titles" among other things may support shared leadership development among group members. Further, communication styles should relax from focused efforts to convince others. Rather, curiosity and a learning orientation should be fostered along with listening, which might include engaging in sense giving (Clark et al. 2010) and forging a learning environment (Weibler and Rohn-Endres 2010).

There may be further possibilities in framing a network coordinator's function and roles (e.g. network coordinative and managing functions, such as acting as relationship manager, integrating and connecting participants). During our fieldwork, we intended to understand whether this may be relevant; however, we finally found that these aspects of the network coordinators' functions were less relevant in understanding the specificity of the leadership-related phenomena in our networks. Rather, the identity-related themes seem to provide more ample scope for supporting shared leadership development. Hence we focused on these aspects, a procedure which is in line with our methodology; it is neither intended nor possible to provide a complete description of emerging empirically grounded phenomena (cf. Charmaz 2014; Suddaby 2006).

\subsection{Limitations and opportunities for future research}

Our contributions must be viewed in the light of potential limitations of our study. First, it is possible that our participants withheld information from us, particularly information that might cast a negative light on their values and motivations for network participation or their ways of exerting influence. However, this problem has probably been mitigated, because we considered multiple perspectives from different data sources, and we looked for coherence in our data (Charmaz 2014). For instance, in the early phase of our research we were surprised by the somewhat striking "harmony" in the network settings. We tried to better understand this phenomenon and learned successively that our participants developed a certain and basically very relaxed attitude toward consensus finding and included this as a subcategory in our analysis. Because nobody is compelled to do anything in the 
network, the collective (leadership) processes that were revealed and appeared to be extremely harmonious are not "always present", and not are easily achieved. Shared leadership will only emerge "voluntarily" based on participants' ideas, values, and actual concerns. Thus, even though differences may exist, they do not necessarily always have to be fully resolved. Second, it was neither possible nor intended to provide an all-encompassing description of facilitators' and interaction dynamics, e.g. related to network evolution or relationship development. Rather, and in line with our grounded theory approach (and its core procedures of constant comparison and theoretical sampling), which implies focused coding and selections, we focused on inductively derived themes that more accurately advance understanding the focal processes of non-leadership emergence and shared leadership development, as summarized in our model. Nevertheless, and third, we recognize that our suggestions with regard to the network level outcomes are an initial step. That is, given our network-centered perspective the assessment of outcomes focuses on the network level and neglects other possible outcomes. Therefore, future research should expand this perspective and assess (ideally various forms of) outcomes at the member organizations' level. Fourth, although our study's findings include individual level dimensions in terms of value orientation and (motivational) orientations towards network engagement, further individual-level/intra-psychical or intrapersonal characteristics such as our participants' personality structures are potentially also relevant and thus deserve further investigation. Finally, concerning the transferability of findings to other contexts, we described the contextual conditions and mapped the domain of our network cases. Based on this, we argue that our suggestions for shared leadership development are limited in their applicability to traditional organization contexts; rather they apply to the core domain of collaborative non-hierarchical network contexts and similar cooperative and low structured organizational settings (e.g. self-managing and self-governing teams/organizations). Future research should further develop our key concepts in relation to other contexts. Beyond that, our grounded theory model provides ample scope for studying various relations in depth. For example, future research should explore in more detail the content of the values and orientations related to jointmotivational network identity. This should involve the study of potential "negative values", which-in contrast to the positive values of network members in our context (cf. RedNet)-would probably not contribute to the common good. Concerning the motivational dimensions of our model, it would be promising to study in more detail how probably existing participants' individual level motivation could be lifted to the (collective) network level.

\section{Conclusion}

Our study comes at a time when collaborative interorganizational networks and similar non-hierarchical forms of organizing with peer-like work settings, for several reasons, are one of the most promising forms of contemporary organizing. In spite of this, (non)leadership phenomena in these context has so far been rarely studied empirically. Hence, understanding how and why leadership actually 
happens, or does not happen, among individuals participating in these network contexts, embedded in collaborative network structures is still scarce. "Taking the lead" in such contexts-so to speak in traditional terms-, implies shifting leadership understanding from the prevalent individual-centered leadership understanding to a collective and identity-based view of leadership. Most basically this is probably grounded on the observation that individuals become in some way empowered by their network-specific embeddedness, and tend to feel a certain aversion to traditional single leadership. However, this is neither the source of anarchy nor the end of leadership, since leadership is acknowledged to be vitally needed for making things happen anyway. Our findings show that individuals embedded in a collaborative non-hierarchical context are likely to develop alternative-i.e. non-individualistic and more relational-concepts of being influential, or refuse leadership in all.

Open Access This article is distributed under the terms of the Creative Commons Attribution 4.0 International License (http://creativecommons.org/licenses/by/4.0/), which permits unrestricted use, distribution, and reproduction in any medium, provided you give appropriate credit to the original author(s) and the source, provide a link to the Creative Commons license, and indicate if changes were made.

\section{References}

Alvesson, M., and A. Spicer. 2012. Critical leadership studies: The case for critical performativity. Human Relations 65: 367-390.

Alvesson, M., and S. Sveningsson. 2003. The great disappearing act: Difficulties in doing "leadership". Leadership Quarterly 14: 359-381.

Alvesson, M. 2017. Leadership: Convergence and divergence in leadership relations. Journal of Management Inquiry 37: 105649261771733. https://doi.org/10.1177/1056492617717339.

Ashforth, B.E., S.H. Harrison, and K.G. Corley. 2008. Identification in organizations: An examination of four fundamental questions. Journal of Management 34: 325-374.

Ashforth, B.E., K.M. Roger, and K.G. Corley. 2011. Identity in organizations: Exploring cross-level dynamics. Organization Science 22: 1144-1156.

Astley, G. 1985. Administrative science as socially constructed truth. Administrative Science Quarterly 30: 497-513.

Avolio, B.J., F. Walumbwa, and T. Weber. 2009. Leadership: Current theories, research, and future directions. Annual Review of Psychology 60: 421-449.

Barringer, B.R., and J.S. Harrison. 2000. Walking a tightrope: Creating value through interorganizational relationships. Journal of Management 26: 367-403.

Beyer, J.M., and L.D. Browning. 1999. Transforming an industry in crisis: Charisma, routinization, and supportive cultural leadership. Leadership Quarterly 10: 483-520.

Blom, M., and M. Alvesson. 2015. All-inclusive and all good: The hegemonic ambiguity of leadership. Scandinavian Journal of Management 31: 480-492.

Borgatti, S.P., and P.C. Foster. 2003. The network paradigm in organizational research: A review and typology. Journal of Management 29: 991-1013.

Charmaz, K. 2014. Constructing grounded theory: A practical guide through qualitative analysis, $2 \mathrm{nd}$ ed. Thousand Oaks: Sage.

Charmaz, K., R. Thornberg, and E. Keane. 2018. Evolving grounded theory and social justice inquiry. In Sage handbook of qualitative research, 5th ed, ed. N.K. Denzin and Y.S. Lincoln, 411-443. Thousand Oaks: Sage.

Connelly, D. 2007. Leadership in the collaborative interorganizational domain. International Journal of Public Administration 30: 1231-1262. 
Chreim, S. 2015. The (non)distribution of leadership roles: Considering leadership practices and configurations. Human Relations 68: 517-543.

Clark, S.M., D.A. Gioia, D.J. Ketchen Jr., and J.B. Thomas. 2010. Transitional identity as a facilitator of organizational identity change during a merger. Administrative Science Quarterly 55: 397-438.

Clegg, S., E. Josserand, A. Mehra, and T.S. Pitsis. 2016. The transformative power of network dynamics: A research agenda. Organization Studies 37: 277-291.

Collinson, D. 2006. Rethinking followership: A post-structuralist analysis of follower identities. Leadership Quarterly 17: 179-189.

Corley, K.G., C.V. Harquail, M.G. Pratt, M.A. Glynn, D. Fiol, and M.J. Hatch. 2006. Guiding organizational identity through aged adolescence. Journal of Management Inquiry 15: 85-99.

Crevani, L., M. Lindgren, and J. Packendorff. 2010. Leadership, not leaders: On the study of leadership as practices and interactions. Scandinavian Journal of Management 26: 77-86.

Currie, G., S. Grubnic, and R. Hodges. 2011. Leadership in public service networks: Antecedents, process, and outcome. Public Administration 89: 242-264.

Davis, J.P., and K.M. Eisenhardt. 2011. Rotating leadership and collaborative innovation: Recombination processes in symbiotic relationships. Administrative Science Quarterly 56: 159-201.

Day, D.V., P. Gronn, and E. Salas. 2004. Leadership capacity in teams. Leadership Quarterly 15: 857-880.

Day, D.V., and M.M. Harrison. 2007. A multilevel, identity-based approach to leadership development. Human Resource Management Review 17: 360-373.

Denis, J.-L., L. Lamothe, and A. Langley. 2001. The dynamics of collective leadership and strategic change in pluralistic organizations. Academy of Management Journal 44: 809-837.

Denis, J.-L., A. Langley, and V. Sergi. 2012. Leadership in the plural. Academy of Management Annals 6: 211-283.

DeRue, D.S., and S.J. Ashford. 2010. Who will lead and who will follow? A social process of leadership identity construction in organizations. Academy of Management Review 35: 627-647.

Dust, S.B., and J.C. Ziegert. 2016. Multi-leader teams in review: A contingent-configuration perspective of effectiveness. International Journal of Management Reviews 18: 518-541.

Edmondson, A.C., and S.E. McManus. 2007. Methodological fit in management field research. Academy of Management Review 32: 1155-1179.

Endres, S., and J. Weibler. 2017. Towards a three-component model of relational social constructionist leadership: A systematic review and critical interpretive synthesis. International Journal of Management Reviews 19: 214-236.

Epitropaki, O., R. Kark, C. Mainemelis, and R.G. Lord. 2017. Leadership and followership identity processes: A multilevel review. Leadership Quarterly 28: 104-129.

Feyerherm, A.E. 1994. Leadership in collaboration: A longitudinal study of two interorganizational rulemaking groups. Leadership Quarterly 5: 253-270.

Fitzsimons, D., K.T. James, and D. Denyer. 2011. Alternative approaches for studying shared and distributed leadership. International Journal of Management Reviews 13: 313-328.

Fjeldstad, Ø.D., C.C. Snow, R.E. Miles, and C. Lettl. 2012. The architecture of collaboration. Strategic Management Journal 33: 734-750.

Gioia, D.A., S.D. Patvardhan, A.L. Hamilton, and K.G. Corley. 2013. Organizational identity formation and change. Academy of Management Annals 7: 123-192.

Glaser, B., and A. Strauss. 1967. The discovery of grounded theory: Strategies for qualitative research. New York: Aldine.

Gephart, R.P. 2004. Qualitative research and the Academy of Management Journal. Academy of Management Journal 47: 454-462.

Gulati, R., P. Puranam, and M. Tushman. 2012. Meta-organization design: Rethinking design in interorganizational and community contexts. Strategic Management Journal 33: 571-586.

Hannah, S.T., J.J. Sumanth, P. Lester, and F. Cavarretta. 2014. Debunking the false dichotomy of leadership idealism and pragmatism: Critical evaluation and support of newer genre leadership theories. Journal of Organizational Behavior 35: 598-621.

Hollander, E.P. 1974. Processes of leadership emergence. Journal of Contemporary Business 3: 19-33.

Hosking, D. 1988. Organizing, leadership and skillful process. Journal of Management Studies 25: 147-166.

Huxham, C., and S. Vangen. 2000. Leadership in the shaping and implementation of collaboration agendas: How things happen in a (not quite) joined-up world. Academy of Management Journal 43: 1159-1175. 
Jack, S.L. 2010. Approaches to studying networks: Implications and outcomes. Journal of Business Venturing 25: 120-137.

Jones, C., W.S. Hesterly, and S.P. Borgatti. 1997. A general theory of network governance: Exchange conditions and social mechanisms. Academy of Management Review 22: 911-945.

Kourti, I. 2017. Why should we collaborate? Exploring partners' interactions in the psychosocial spaces of an inter-organisational collaboration. Scandinavian Journal of Management 33: 93-101.

Larson, M., and E. Wikström. 2007. Relational interaction processes in project networks: The consent and negotiation perspectives. Scandinavian Journal of Management 23: 327-352.

Lindgren, M., and J. Packendorff. 2011. Issues, responsibilities and identities: A distributed leadership perspective on biotechnology R\&D management. Creativity and Innovation Management 20: $157-170$.

Martin, G.P., G. Currie, and R. Finn. 2009. Leadership, service reform, and public-service networks: The case of cancer-genetics pilots in the English NHS. Journal of Public Administration Research and Theory 19: 769-794.

Miles, R.E., C.C. Snow, Ø.D. Fjeldstad, G. Miles, and C. Lettl. 2010. Designing organizations to meet 21st-century opportunities and challenges. Organizational Dynamics 39: 93-103.

Morgan, G., and L. Smircich. 1980. The case for qualitative research. Academy of Management Review 5: 491-500.

Müller-Seitz, G. 2012. Leadership in interorganizational networks: A literature review and suggestions for future research. International Journal of Management Reviews 4: 428-443.

Nicolaides, V.C., K.A. LaPort, T.R. Chen, A.J. Tomassetti, E.J. Weis, S.J. Zaccaro, and J.M. Cortina. 2014. The shared leadership of teams: A meta-analysis of proximal, distal, and moderating relationships. Leadership Quarterly 25: 923-942.

Ospina, S.M., and A. Saz-Carranza. 2010. Paradox and collaboration in network management. Administration and Society 42: 404-440.

Paunova, M. 2015. The emergence of individual and collective leadership in task groups: A matter of achievement and ascription. Leadership Quarterly 26: 935-957.

Pearce, C.L., and J.A. Conger. 2003. All those years age. The theoretical underpinnings of shared leadership. In Shared leadership. Reframing the hows and whys of leadership, ed. C.L. Pearce and J.A. Conger, 1-18. Thousand Oaks: Sage.

Powell, W.W. 1990. Neither market nor hierarchy. Network forms of organization. Research in Organizational Behavior 12: 295-336.

Provan, K.G., A. Fish, and J. Sydow. 2007. Interorganizational networks at the network level: A review of the empirical literature on whole networks. Journal of Management 33: 479-516.

Raab, J., and P. Kenis. 2009. Heading toward a society of networks: Empirical developments and theoretical challenges. Journal of Management Inquiry 18: 198-210.

Ridder, H. 2017. The theory contribution of case study research designs. Business Research 10: 281-305.

Ritala, P., L. Armila, and K. Blomqvist. 2009. Innovation orchestration capability-defining the organizational and individual level determinants. International Journal of Innovation Management 13: 569-591.

Saz-Carranza, A., and S. Ospina. 2011. The behavioral dimension of governing interorganizational goaldirected networks-managing the unity-diversity tension. Journal of Public Administration Research and Theory 21: 327-365.

Sergi, V., J.-L. Denis, and A. Langley. 2012. Opening up perspectives on plural leadership. Industrial and Organizational Psychology 5: 403-436.

Stone, T.H., and W.H. Cooper. 2009. Emerging credits. Leadership Quarterly 20: 785-798.

Strauss, A.L., and J.M. Corbin. 1998. Basics of qualitative research: Techniques and procedures for developing grounded theory, 2nd ed. Thousand Oaks: Sage.

Suddaby, R. 2006. What grounded theory is not. Academy of Management Journal 49: 633-642.

Sydow, J., F. Lerch, C. Huxham, and P. Hibbert. 2011. A silent cry for leadership: Organizing for leading (in)clusters. Leadership Quarterly 22: 328-343.

Uhl-Bien, M. 2006. Relational leadership theory: Exploring the social processes of leadership and organizing. Leadership Quarterly 17: 654-676.

Uhl-Bien, M., and S. Ospina. 2012. Advancing relational leadership. A dialogue among perspectives. Charlotte: Information Age.

Vangen, S., and C. Huxham. 2003. Enacting leadership for collaborative advantage: Dilemmas of ideology and pragmatism in the activities of partnership managers. British Journal of Management 14: S61-S76. 
Van Maanen, J. 1979. The fact of fiction in organizational ethnography. Administrative Science Quarterly 24: 539-550.

Wellman, N. 2017. Authority or community? A relational models theory of group-level leadership emergence. Academy of Management Review 42: 596-617.

Weibler, J., and S. Rohn-Endres. 2010. Learning conversation and shared network leadership development, gestalt, and consequences. Journal of Personnel Psychology 9: 181-194.

White, L., G. Currie, and A. Lockett. 2016. Pluralized leadership in complex organizations: Exploring the cross network effects between formal and informal leadership relations. Leadership Quarterly 27: 280-297.

Publisher's Note Springer Nature remains neutral with regard to jurisdictional claims in published maps and institutional affiliations. 